\title{
Injection of hydrogel spacer increased maximal intrafractional prostate motion in anterior and superior directions during volumetric modulated arc therapy-stereotactic body radiation therapy for prostate cancer
}

Subaru Sawayanagi, Hideomi Yamashita*, Mami Ogita, Ryosuke Takenaka, Yuki Nozawa, Yuichi Watanabe, Toshikazu Imae and Osamu Abe

\begin{abstract}
Background: The aim of this study was to clarify the association between intrafractional prostate shift and hydrogel spacer.

Methods: Thirty-eight patients who received definitive volumetric modulated arc therapy (VMAT)-stereotactic body radiation therapy (SBRT) for prostate cancer with prostate motion monitoring in our institution in 2018-2019 were retrospectively evaluated. In order to move the rectum away from the prostate, hydrogel spacer (SpaceOAR system, Boston Scientific, Marlborough, the United States) injection was proposed to the patients as an option in case of meeting the indication of use. We monitored intrafractional prostate motion by using a 4-dimensional (4D) transperineal ultrasound device: the Clarity 4D ultrasound system (Elekta AB). The deviation of the prostate was monitored in each direction: superior-inferior, left-right, and anterior-posterior. We also calculated the vector length. The maximum intrafractional displacement (MID) per fraction for each direction was detected and mean of MIDs was calculated per patient. The MIDs in the non-spacer group and the spacer group were compared using the unpaired t-test.

Results: We reviewed 33 fractions in eight patients as the spacer group and 148 fractions in 30 patients as the non-spacer group. The superior MID was $0.47 \pm 0.07$ (mean $\pm S E$ ) $\mathrm{mm}$ versus $0.97 \pm 0.24 \mathrm{~mm}(P=0.014$ ), the inferior MID was $1.07 \pm 0.11 \mathrm{~mm}$ versus $1.03 \pm 0.25 \mathrm{~mm}(P=0.88)$, the left MID was $0.74 \pm 0.08 \mathrm{~mm}$ versus $0.87 \pm 0.27 \mathrm{~mm}$ $(P=0.55)$, the right MID was $0.67 \pm 0.08 \mathrm{~mm}$ versus $0.92 \pm 0.21 \mathrm{~mm}(P=0.17)$, the anterior MID was $0.45 \pm 0.06 \mathrm{~mm}$ versus $1.16 \pm 0.35 \mathrm{~mm}(P=0.0023)$, and the posterior MID was $1.57 \pm 0.17 \mathrm{~mm}$ versus $1.37 \pm 0.22 \mathrm{~mm}(P=0.56)$ in the non-spacer group and the spacer group, respectively. The max of $V L$ was $2.24 \pm 0.19 \mathrm{~mm}$ versus $2.89 \pm 0.62 \mathrm{~mm}$ $(P=0.19)$, respectively.
\end{abstract}

*Correspondence: yamachan07291973@yahoo.co.jp Department of Radiology, University of Tokyo Hospital, 7-3-1, Hongo, Bunkyo-ku, Tokyo 113-8655, Japan permits use, sharing, adaptation, distribution and reproduction in any medium or format, as long as you give appropriate credit to the original author(s) and the source, provide a link to the Creative Commons licence, and indicate if changes were made. The images or other third party material in this article are included in the article's Creative Commons licence, unless indicated otherwise in a credit line to the material. If material is not included in the article's Creative Commons licence and your intended use is not permitted by statutory regulation or exceeds the permitted use, you will need to obtain permission directly from the copyright holder. To view a copy of this licence, visit http://creativecommons.org/licenses/by/4.0/. The Creative Commons Public Domain Dedication waiver (http://creativeco mmons.org/publicdomain/zero/1.0/) applies to the data made available in this article, unless otherwise stated in a credit line to the data. 
Conclusions: Our findings suggest that maximum intrafractional prostate motion during VMAT-SBRT was larger in patients with hydrogel spacer injection in the superior and anterior directions. Since this difference seemed not to disturb the dosimetric advantage of the hydrogel spacer, we do not recommend routine avoidance of the hydrogel spacer use.

Keywords: Prostate cancer, Stereotactic body radiation therapy, Intrafractional prostate motion, Transperineal ultrasound, Hydrogel spacer

\section{Background}

External beam radiation therapy (EBRT) is recognized as one of the primary treatment options for patients with prostate cancer (PCa) [1,2]. Intensity modulated radiation therapy (IMRT) with image-guided radiation therapy (IGRT) technique is currently the gold standard for EBRT. A low $\alpha / \beta$ ratio of PCa has encouraged hypofractionation and stereotactic body radiation therapy (SBRT), or extreme hypofractionation, which is currently considered as a promising option of EBRT [3-6]. Recently, the trial of the single-fraction SBRT for localized prostate cancer under the intrafractional tracking was reported [7]. While higher quality of positioning is required in SBRT to optimize treatments, it is known that organs in pelvis including prostate are shifting under the influence of rectal volume, bladder volume, and change of muscle tension among other things [8-17]. These intrafractional uncertainties possibly affect the dose distributions [18-20].

Less is known about risk factors related to intrafractional prostate motion. While the variability in location of external skin markers relative to internal anatomy in obese patients caused a significant difference in terms of interfractional prostate shift [21], there was no relationship between body mass index (BMI) and intrafractional prostate motion [22]. It was reported that the shorter the maximum rectal diameter is, the less the intrafractional prostate motion is [23].

The injection of hydrogel spacer between the prostate and the rectum has been introduced for RT for PCa to separate the prostate from the anterior wall of the rectum, which contributes to reducing the RT dose of the rectum and reduces gastrointestinal and genitourinary toxicities [24-27]. On the other hand, the complications related to the injection of hydrogel spacer have been reported [27, 28]. Regarding prostate motion, it was shown that the insertion of hydrogel spacer did not greatly limit interfractional and intrafractional prostate displacements [29-33]. We hypothesized that the hydrogel spacer potentially implicates the prostate variability during RT. The aim of this study was to clarify the association between the intrafractional prostate shift and the hydrogel spacer.

\section{Methods}

A total of 38 patients with histologically confirmed prostate cancer who received definitive volumetric modulated arc therapy (VMAT)-SBRT with prostate motion monitoring with or without androgen deprivation therapy (ADT) for PCa in our institution in 2018-2019 were retrospectively evaluated. The study was reviewed and approved by the institutional review board and ethics committee. Examination number was 3372.

\section{Radiotherapy}

A total dose of 36.25-40 Gy in five fractions was prescribed to $95 \%$ of the planning target volume (PTV) every other weekday. All patients received CT scans which were reconstructed 1-mm-thick slices with a full bladder for treatment planning. A rectal enema was prescribed before simulation and before each treatment session to empty the contents of the rectum. The clinical target volume (CTV) consisted of prostate with or without seminal vesicles according to the risk classification of the NCCN guidelines version 1.2018. The CTV was extended by $5 \mathrm{~mm}$ in every direction except posterior with $3 \mathrm{~mm}$ extension to generate the PTV. We used Monaco (Elekta $\mathrm{AB}$, Stockholm, Sweden) as the treatment planning system. In order to move the rectum away from the prostate, the hydrogel spacer (SpaceOAR system, Boston Scientific, Marlborough, the United States) was transperineally injected into the recto-prostatic space of patients who hoped to receive it in case of meeting the indication of use. KV cone beam CT (CBCT) scans were acquired after the setup before each treatment session to reduce the interfraction error of patient positioning.

\section{Motion monitoring}

Intrafraction motion of the prostate was monitored by a 4-dimensional (4D) transperineal ultrasound (US) device: the Clarity 4D ultrasound system (Elekta $\mathrm{AB}$ ) with an autoscanning perineal US probe. We regarded the prostate position when CBCT scans finished as the baseline position. Monitoring time was defined as the time from the end of CBCT to the end of radiation. We verified these time points with the logs in the Clarity system. The deviation of the prostate from the baseline position was 
monitored as a function of time along the three directions: superior-inferior (SI), left-right (LR), and anterior-posterior (AP). We also calculated the vector length $(\mathrm{VL})$ at each point in time.

Large spike-like prostate displacement was seen during couch shift for patient position adjustment in some fractions though the prostate position we evaluated was relative to the couch position. These spike-like displacements continued for about $10 \mathrm{~s}$. We excluded these displacements from analyses because all patients immediately recovered from this error before the start of radiation. The maximum intrafractional displacement (MID), the mean intrafractional displacement (mID), and the 95th percentile maximum intrafractional displacement (95thMID) per fraction for each direction was detected and mean of them was calculated per patient. The 95th-MID was the value within which the prostate displacement was during $95 \%$ of the monitoring time. We chose these objects for our study for the following reasons. Ignoring the interfractional errors, in other words, hypothesizing that we can perfectly bring the patient to the treatment position using CBCT, the MID for each direction was the margin itself we needed to add to the CTV in order to include all the errors into the irradiated field of the single treatment. To exclude the extreme movement in a very short time, we also analyzed the 95th-MID. We can recognize which direction and how far the prostate tends to move during the monitoring time by the mIDs.

The Stroom formula [34] $(=2.0 \Sigma+0.7 \sigma)$ and the van Herk formula [35] $(=2.5 \Sigma+0.7 \sigma)$ were used to calculate the CTV-PTV margin derived from intrafractional error, where $\Sigma$ is the systematic error and $\sigma$ is the random error.

\section{Statistical analysis}

Differences in characteristic variables between patients without spacer and those with spacer were tested using the $x^{2}$-test for categorical variables and the unpaired t-test for continuous variables. In this study, the volume from the slice $1 \mathrm{~cm}$ above the highest part of the PTV to the slice $1 \mathrm{~cm}$ below the lowest part of the PTV in axial slices was considered as rectum volume. Bladder volume in this context included internal urine. The MIDs, the mIDs, and the 95th-MIDs in the non-spacer group and the spacer group were compared using the unpaired t-test. Multiple regression analysis was used to detect risk factors related to the MID. All statistical analyses were two-sided and performed using $\mathrm{R}$, version 4.0.3. Results were considered statistically significant at $P<0.05$.

\section{Results}

\section{Patient characteristics}

We reviewed 33 fractions in eight patients as the spacer group and 148 fractions in 30 patients as the non-spacer group. The baseline patient characteristics were presented in Table 1 . There was no statistically significant difference between the two groups except for rectal volume. The median age was 73 (58-85) and 79 (66-84) years $(P=0.22)$ and the mean monitoring time was $275 \pm 42($ mean $\pm S D)$ and $279 \pm 33 \mathrm{~s}(P=0.82)$ in the non-spacer group and the spacer group, respectively. Twenty-one patients (70.0\%) in the non-spacer group and six patients $(75.0 \%)$ in the spacer group received neoadjuvant ADT $(P=0.99)$, respectively. The mean BMI was $23.5 \pm 2.7$ and $23.6 \pm 3.4 \mathrm{~kg} / \mathrm{m}^{2}$ in the non-spacer group and the spacer group, respectively $(P=0.93)$. Nine patients $(30.0 \%)$ in the non-spacer and one patient $(12.5 \%)$ in the spacer group underwent abdominal surgery before $\mathrm{RT}$, respectively $(P=0.65)$. The mean volume of prostate (non-spacer vs. spacer group, $31.1 \pm 12.4 \mathrm{cc}$ vs. $25.0 \pm 9.2 \mathrm{cc}, P=0.22)$ and bladder $(277.1 \pm 169.2 \mathrm{cc}$ vs. $205.2 \pm 77.9 \mathrm{cc}, P=0.26)$ measured on planning CT in each group was not significantly different. The rectum volume on planning $\mathrm{CT}$ in the non-spacer group was larger than the spacer group $(55.4 \pm 15.5$ cc vs. $43.4 \pm 9.0 \mathrm{cc}, P=0.047$ ).

\section{Motion analysis}

The comparison of MID, mID, and 95th-MID for each direction and the VL between the two groups was presented in Table 2 and the boxplots of the MIDs were shown in Fig. 1. The superior MID was $0.47 \pm 0.07$ (mean $\pm \mathrm{SE}$ ) $\mathrm{mm}$ versus $0.97 \pm 0.24 \mathrm{~mm}$ $(P=0.014)$, the inferior MID was $1.07 \pm 0.11 \mathrm{~mm}$ versus $1.03 \pm 0.25 \mathrm{~mm}(P=0.88)$, the left MID was $0.74 \pm 0.08 \mathrm{~mm}$ versus $0.87 \pm 0.27 \mathrm{~mm}(P=0.55)$, the right MID was $0.67 \pm 0.08 \mathrm{~mm}$ versus $0.92 \pm 0.21 \mathrm{~mm}$ $(P=0.17)$, the anterior MID was $0.45 \pm 0.06 \mathrm{~mm}$ versus $1.16 \pm 0.35 \mathrm{~mm}(P=0.0023)$, the posterior MID was $1.57 \pm 0.17 \mathrm{~mm}$ versus $1.37 \pm 0.22 \mathrm{~mm}(P=0.56)$, and the MID as VL was $2.24 \pm 0.19 \mathrm{~mm}$ versus $2.89 \pm 0.62 \mathrm{~mm}(P=0.19)$ in the non-spacer group and the spacer group, respectively. The superior-inferior $\mathrm{mID}$ was $-0.34 \pm 0.06 \mathrm{~mm}$ versus $-0.12 \pm 0.19 \mathrm{~mm}$ $(P=0.16)$, the left-right $\mathrm{mID}$ was $0.02 \pm 0.04 \mathrm{~mm}$ versus $0.04 \pm 0.25 \mathrm{~mm}(P=0.93)$, the anterior-posterior mID was $-0.55 \pm 0.09 \mathrm{~mm}$ versus $-0.21 \pm 0.27 \mathrm{~mm}$ $(P=0.13)$, the $\mathrm{mID}$ as VL was $1.05 \pm 0.10 \mathrm{~mm}$ versus $1.56 \pm 0.43 \mathrm{~mm}(P=0.10)$ in the non-spacer group and the spacer group, respectively. The prostate tended to move caudally and posteriorly with or without the spacer. The superior 95th-MID was $0.27 \pm 0.05 \mathrm{~mm}$ versus $0.74 \pm 0.19 \mathrm{~mm}(P=0.0029)$, the inferior 95thMID was $0.87 \pm 0.09 \mathrm{~mm}$ versus $0.83 \pm 0.25 \mathrm{~mm}$ $(P=0.87)$, the left 95 th-MID was $0.51 \pm 0.07 \mathrm{~mm}$ versus $0.61 \pm 0.24 \mathrm{~mm}(P=0.60)$, the right 95th-MID was $0.41 \pm 0.06 \mathrm{~mm}$ versus $0.64 \pm 0.18 \mathrm{~mm}(P=0.17)$, 
Table 1 Baseline patient characteristics

\begin{tabular}{|c|c|c|c|}
\hline Parameter & $\begin{array}{l}\text { Non-spacer group } \\
N=30\end{array}$ & $\begin{array}{l}\text { Spacer group } \\
N=8\end{array}$ & $P$ value \\
\hline Age, years, median (range) & $73(58-85)$ & $79(66-84)$ & $0.22^{b}$ \\
\hline Body mass index, mean $\pm S D$ & $23.5 \pm 2.7$ & $23.6 \pm 3.4$ & $0.93^{b}$ \\
\hline Clinical T stage, n (\%) & & & $0.78^{c}$ \\
\hline $1 \mathrm{c}$ & $6(20 \%)$ & $3(37.5 \%)$ & \\
\hline $2 a$ & $13(43.3 \%)$ & $2(25.0 \%)$ & \\
\hline $2 b$ & $2(6.7 \%)$ & $1(12.5 \%)$ & \\
\hline $2 c$ & $5(16.7 \%)$ & $2(25.0 \%)$ & \\
\hline $3 a$ & $1(3.3 \%)$ & $0(0 \%)$ & \\
\hline $3 b$ & $2(6.7 \%)$ & $0(0 \%)$ & \\
\hline 4 & $1(3.3 \%)$ & $0(0 \%)$ & \\
\hline Mean monitoring time, seconds, mean $\pm S D$ & $275 \pm 42$ & $279 \pm 33$ & $0.82^{b}$ \\
\hline Neoadjuvant ADT, n (\%) & & & $0.99^{c}$ \\
\hline No & $9(30.0 \%)$ & $2(25.0 \%)$ & \\
\hline Yes & $21(70.0 \%)$ & $6(75.0 \%)$ & \\
\hline History of abdominal surgery, n (\%) & & & $0.65^{c}$ \\
\hline No & $21(70.0 \%)$ & $7(87.5 \%)$ & \\
\hline Yes & $9(30.0 \%)$ & $1(12.5 \%)$ & \\
\hline Prostate volume* ${ }^{*}, \mathrm{cc}$, mean \pm SD & $31.1 \pm 12.4$ & $25.0 \pm 9.2$ & $0.22^{\mathrm{b}}$ \\
\hline Rectum volume ${ }^{* a}, c c$, mean $\pm S D$ & $55.4 \pm 15.5$ & $43.4 \pm 9.0$ & $0.047^{\mathrm{bt}}$ \\
\hline Bladder volume*, $c c$, mean \pm SD & $277.1 \pm 169.2$ & $205.1 \pm 77.9$ & $0.26^{b}$ \\
\hline
\end{tabular}

Abbreviations: $A D T$ androgen deprivation therapy, SD standard deviation

*Measured on planning CT

${ }^{\text {a }}$ From the slice $1 \mathrm{~cm}$ above the PTV to the slice $1 \mathrm{~cm}$ below the PTV in axial slices

${ }^{b}$ By unpaired t-test

${ }^{\mathrm{C}}$ By $\mathrm{x}^{2}$-test

† Statistically significant

the anterior 95th-MID was $0.23 \pm 0.04 \mathrm{~mm}$ versus $0.85 \pm 0.31 \mathrm{~mm}(P=0.0020)$, the posterior 95th-MID was $1.31 \pm 0.16 \mathrm{~mm}$ versus $1.05 \pm 0.14 \mathrm{~mm}(P=0.42)$, and the 95th-MID as VL was $1.89 \pm 0.18 \mathrm{~mm}$ versus $2.51 \pm 0.55 \mathrm{~mm}(P=0.19)$ in the non-spacer group and the spacer group, respectively. The superior and anterior MIDs and 95th-MIDs were smaller in the non-spacer group, while the other MIDs, mIDs, and 95th-MIDs were not significantly different in the two groups.

\section{Multivariate analysis}

The results of multivariate analyses for MIDs for each direction were shown in Table 3 . We included age, spacer injection, rectum volume, and the duration of monitoring as explanatory variables. Spacer injection was the independent risk factor of superior and anterior MIDs. There was no independent risk factor of inferior, left, right, and posterior MIDs and maximum VL.

\section{Margin calculation}

The mean $(\mu)$, the systematic error $(\Sigma)$, and the random error $(\sigma)$ of intrafractional shift of the prostate were $\mu=(-0.43,0.06,-1.12) \mathrm{mm}, \Sigma=(0.91,0.78,1.17) \mathrm{mm}$, and $\sigma=(1.24,1.25,1.86) \mathrm{mm}$ in the SI, LR, and AP directions, respectively in the non-spacer group. In the spacer group, $\mu=(-0.79,0.18,-0.71) \mathrm{mm}, \Sigma=(1.12,1.01$, 1.32) $\mathrm{mm}$ and $\sigma=(2.12,1.21,2.42) \mathrm{mm}$, respectively. According to the Stroom formula, margins (M) were as follows: $\mathrm{M}=(2.69,2.42,3.64) \mathrm{mm}$ in the SI, LR, and AP directions in the non-spacer group, and $\mathrm{M}=(3.71,2.87$, 4.34) $\mathrm{mm}$ in the spacer group. According to the van Herk formula, $\mathrm{M}=(3.14,2.81,4.23) \mathrm{mm}$ in the non-spacer group and $\mathrm{M}=(4.27,3.37,5.00) \mathrm{mm}$ in the spacer group, respectively.

\section{Discussion}

Nowadays, hydrogel spacer is widely used for the radiotherapy for prostate cancer. It has been shown that the hydrogel spacer improves the dose distribution and 
Table 2 Mean of the intrafractional displacements per patient

\begin{tabular}{|c|c|c|c|}
\hline Direction & $\begin{array}{l}\text { Non-spacer group } \\
N=30 \\
\mathrm{~mm}, \text { Mean } \pm \mathrm{SE}\end{array}$ & $\begin{array}{l}\text { Spacer group } \\
N=8 \\
\text { mm, Mean } \pm S E\end{array}$ & $P$ value $^{\mathrm{a}}$ \\
\hline \multicolumn{4}{|c|}{ Maximum intrafractional displacements } \\
\hline Superior & $0.47 \pm 0.07$ & $0.97 \pm 0.24$ & $0.014^{\dagger}$ \\
\hline Inferior & $1.07 \pm 0.11$ & $1.03 \pm 0.25$ & 0.88 \\
\hline Left & $0.74 \pm 0.08$ & $0.87 \pm 0.27$ & 0.55 \\
\hline Right & $0.67 \pm 0.08$ & $0.92 \pm 0.21$ & 0.17 \\
\hline Anterior & $0.45 \pm 0.06$ & $1.16 \pm 0.35$ & $0.0023^{\dagger}$ \\
\hline Posterior & $1.57 \pm 0.17$ & $1.37 \pm 0.22$ & 0.56 \\
\hline Vector length & $2.24 \pm 0.19$ & $2.89 \pm 0.62$ & 0.19 \\
\hline \multicolumn{4}{|c|}{ Mean intrafracitonal displacements ${ }^{b}$} \\
\hline Superior-inferior & $-0.34 \pm 0.06$ & $-0.12 \pm 0.19$ & 0.16 \\
\hline Left-right & $0.02 \pm 0.04$ & $0.04 \pm 0.25$ & 0.93 \\
\hline Anterior-posterior & $-0.55 \pm 0.09$ & $-0.21 \pm 0.27$ & 0.13 \\
\hline Vector length & $1.05 \pm 0.10$ & $1.56 \pm 0.43$ & 0.10 \\
\hline \multicolumn{4}{|c|}{ 95th percentile intrafractional displacements } \\
\hline Superior & $0.27 \pm 0.05$ & $0.74 \pm 0.19$ & $0.0029^{\dagger}$ \\
\hline Inferior & $0.87 \pm 0.09$ & $0.83 \pm 0.25$ & 0.87 \\
\hline Left & $0.51 \pm 0.07$ & $0.61 \pm 0.24$ & 0.60 \\
\hline Right & $0.41 \pm 0.06$ & $0.64 \pm 0.18$ & 0.17 \\
\hline Anterior & $0.23 \pm 0.04$ & $0.85 \pm 0.31$ & $0.0020^{\dagger}$ \\
\hline Posterior & $1.31 \pm 0.16$ & $1.05 \pm 0.14$ & 0.42 \\
\hline Vector length & $1.89 \pm 0.18$ & $2.51 \pm 0.55$ & 0.19 \\
\hline
\end{tabular}

Abbreviations: SE standard error

${ }^{a}$ By unpaired t-test

${ }^{\mathrm{b}}$ Superior, left, and anterior displacements were written as positive number

${ }^{\dagger}$ Statistically significant

reduces gastrointestinal and genitourinary toxicities [24-27], while some complications related to the injection were observed $[27,28]$. They included anaphylaxis, colostomy, pulmonary embolism, and prostatic abscess. Routine use of the hydrogel spacer is still controversial.

We investigated the intrafractional prostate motion during VMAT-SBRT for PCa. Considering that SE of the MID, the mID, and the 95th-MID was small enough in each direction, these outcomes seemed to be correctly averaged. Calculated margins according to the Stroom formula were larger in the spacer group than the non-spacer group by $(1.02,0.45,0.70) \mathrm{mm}$ in the SI, $\mathrm{LR}$, and AP directions, respectively. Based on the van Herk formula, calculated margins were larger in the spacer group than the non-spacer group by $(1.13,0.56$, 0.77) $\mathrm{mm}$ in the SI, LR, and AP directions, respectively.

Errors related to the quality of radiotherapy are categorized into interfractional errors and intrafractional errors. While interfractional errors can be minimized by using high-precision techniques of patient positioning, intrafractional errors caused by organ motion depended on the patient himself and are difficult to be controlled.

Development of monitoring devices has contributed to knowing the intrafrational organ motions. Mah et al. [8] investigated the intrafractional prostate motion of 42 patients with prostate cancer using cine-MRI. They reported that the displacements of prostate $($ mean $\pm \mathrm{SD})$ were $0.0 \pm 3.4 \mathrm{~mm}, 0.0 \pm 1.5 \mathrm{~mm}, 0.2 \pm 2.9 \mathrm{~mm}$ in the SI, LR, and AP dimensions, respectively. Willoughby et al. [12] used the Calypso 4D localization system which is real-time tracking system with implanted electromagnetic transponders to track the intrafractional shift of prostate. They showed that the average $( \pm S D)$ of the maximum differences in 11 cases were $3.61 \pm 3.13 \mathrm{~mm}$, $0.91 \pm 0.35 \mathrm{~mm}, 3.92 \pm 4.32 \mathrm{~mm}$ in the SI, LR, and AP directions, respectively. Pinkawa et al. [14] demonstrated that the intrafractional displacements of prostate $($ mean $\pm \mathrm{SD})$ were $0.0 \pm 2.0 \mathrm{~mm}, 0.2 \pm 1.9 \mathrm{~mm}$, $0.6 \pm 2.2 \mathrm{~mm}$ in the SI, LR, and AP directions in 32 patients with prostate cancer by using transabdominal US tracking system. Comparable level of the intrafractional prostate motion with these studies was seen in our study. The average $( \pm \mathrm{SE})$ of the maximum vector displacement was $2.24 \pm 0.19 \mathrm{~mm}$ and $2.89 \pm 0.62 \mathrm{~mm}$ in the non-spacer and the spacer group, respectively.

Sihono et al. [15] suggested the patient populationbased margin according to the van Herk formula is as follows: $1.10 \mathrm{~mm}, 1.25 \mathrm{~mm}$, and $1.33 \mathrm{~mm}$ in the SI, LR, and AP directions, respectively. They used the Clarity system just like our study. We demonstrated the larger margins calculated based on our population; $3.14 \mathrm{~mm}$, $2.81 \mathrm{~mm}, 4.23 \mathrm{~mm}$ in the non-spacer group and $4.27 \mathrm{~mm}$, $3.37 \mathrm{~mm}, 5.00 \mathrm{~mm}$ in the spacer group. The difference is probably ascribed to the fact that Sihono et al. may have used mean intrafractional motion for margin calculation, whereas we used maximum intrafractional motion. The mean intrafractional prostate displacement by Richter et al. [16], who also used the Clarity system, was remarkably little: $-0.06 \pm 0.49 \mathrm{~mm},-0.09 \pm 0.61 \mathrm{~mm}$, and $-0.01 \pm 0.78 \mathrm{~mm}$ in the SI, LR and AP directions, respectively. Levin-Epstein et al. [17] reported that the margins calculated with the intra-fractional motion were $2.7 \mathrm{~mm}, 1.9 \mathrm{~mm}$, and $3.1 \mathrm{~mm}$ in the SI, LR, and AP directions, respectively.

Knowledge about parameters related to intrafractional prostate motion is absolutely limited. Brown et al. [22] showed that there was no statistically significant relationship between intrafractional prostate motion and BMI by using linear regression analysis. Oates et al. [23] investigated a relationship between maximum rectal diameter (MRD) and intrafractional prostate motion. They showed with $90 \%$ confidence that for a MRD $\leq 3 \mathrm{~cm}$, prostate displacement will be $\leq 5 \mathrm{~mm}$ and that for a $M R D \leq 3.5 \mathrm{~cm}$, 

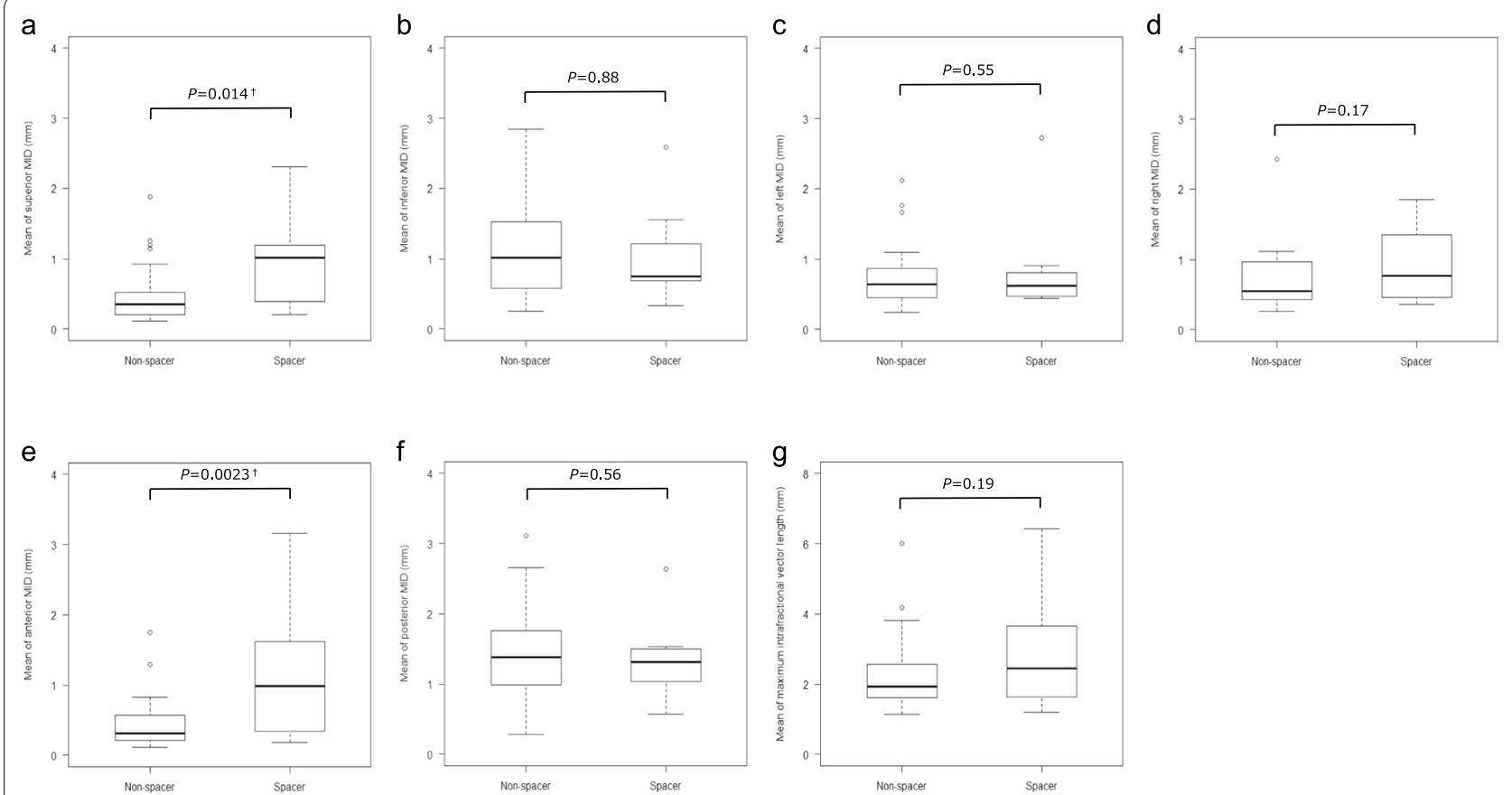

Fig. 1 Boxplots of the maximum intrafractional displacement. a Mean of superior MID. b Mean of inferior MID. c Mean of left MID. d Mean of right MID. e Mean of anterior MID. $\mathbf{f}$ Mean of posterior MID. $\mathbf{g}$ Mean of maximum intrafractional vector length. Abbreviations: MID maximum intrafracitonal displacement. 'Statistically significant

prostate displacement will be $\leq 5.5 \mathrm{~mm}$. By prescribing a rectal enema and performing $\mathrm{CBCT}$ before each treatment session, the variety of MRD may have been minimized in our study. Rectum volume was smaller in the spacer group, which may be caused by the deformation of rectum by the pressure from the anterior direction by the injected hydrogel spacer (Fig. 2). However, rectum volume was not an independent risk factor for prostate displacement in the multivariate analysis. The displacement of prostate was shown to be smaller in step-andshoot IMRT fractions than in VMAT fractions due to the shorter treatment time of VMAT by Ballhausen et al. [36]. In the present study, we treated all patients with VMAT using flattening filter free (FFF) beams and monitoring time from the end of $\mathrm{CBCT}$ to the end of radiation was about $4.5 \mathrm{~min}$. According to our study, monitoring time did not significantly affect prostate shift.

Picardi et al. [30] showed that hydrogel spacer injection into the recto-prostatic space did not significantly influence the interfraction prostate motion based on the analysis using implanted fiducial markers and CBCT. It was reported that hydrogel spacer insertion significantly reduced the intrafraction rotational shift in the AP direction on cine-MRI by Cuccia et al. [31] and they concluded that hydrogel spacer contributed to limiting prostate intrafractional motion. On the other hand, Juneja et al. [29] showed that the average of the mean intrafractional vector displacement of prostate was significantly larger in patients with hydrogel spacer than those without spacer by analyzing the implanted electromagnetic markers position on $\mathrm{kV}$ fluoroscopy. The difference between the two groups was $0.4 \mathrm{~mm}$ on their study. In our study, there was no significant difference in maximum VL, whereas superior and anterior MIDs were significantly larger in the spacer group in our study, and the difference between the two groups were $0.5 \mathrm{~mm}$ in the superior direction and $0.7 \mathrm{~mm}$ in the anterior direction. Suzuki et al. [32] also reported the effect of the hydrogel spacer on the intrafractional prostate motion during the CyberKnife treatment for prostate cancer. They calculated the mean intrafractional prostate motion in the SI, LR, and AP directions for each patient using two fiducial markers and $\mathrm{kV} \mathrm{X}$-ray images and compared the results of the spacer group with the non-spacer group. There was no statistically significant difference between the two groups in any directions.

The present study was associated with some limitations. One of the major limitations was the fact that we did not investigate the effect of the intrafractional prostate motion on the dosimetric and clinical outcome. $\mathrm{Li}$ et al. [37] suggested an analytical model for the estimation of respiratory motion-induced dose uncertainty in spot-scanning proton beam therapy. Kontaxis et al. [20] quantified the delivered dose for the prostate cancer 
Table 3 Multivariate analyses for maximum intrafractional displacement

\begin{tabular}{|c|c|c|}
\hline & Regression coefficient $(95 \% \mathrm{Cl})$ & $P$ value $^{\mathrm{a}}$ \\
\hline \multicolumn{3}{|l|}{ Superior MID } \\
\hline Age (continuous) & $-0.012(-0.036-0.012)$ per year & 0.31 \\
\hline Spacer injection & & $0.014^{\dagger}$ \\
\hline Non-spacer & Reference & \\
\hline Spacer & $0.546(0.118-0.975)$ & \\
\hline Rectum volume (continuous) & $0.001(-0.001-0.013)$ per $c c$ & 0.80 \\
\hline Monitoring time (continuous) & $0.001(-0.003-0.005)$ per second & 0.66 \\
\hline \multicolumn{3}{|l|}{ Inferior MID } \\
\hline Age (continuous) & $0.026(-0.003-0.055)$ per year & 0.082 \\
\hline Spacer injection & & 0.31 \\
\hline Non-spacer & Reference & \\
\hline Spacer & $-0.263(-0.783-0.256)$ & \\
\hline Rectum volume (continuous) & $-0.011(-0.025-0.002)$ per cc & 0.10 \\
\hline Monitoring time (continuous) & $0.000(-0.005-0.005)$ per second & 0.99 \\
\hline \multicolumn{3}{|l|}{ Left MID } \\
\hline Age (continuous) & $0.011(-0.015-0.038)$ per year & 0.39 \\
\hline Spacer injection & & 0.70 \\
\hline Non-spacer & Reference & \\
\hline Spacer & $0.089(-0.382-0.560)$ & \\
\hline Rectum volume (continuous) & $0.000(-0.012-0.013)$ per $c c$ & 0.98 \\
\hline Monitoring time (continuous) & $0.000(-0.005-0.004)$ per second & 0.84 \\
\hline \multicolumn{3}{|l|}{ Right MID } \\
\hline Age (continuous) & $0.008(-0.015-0.031)$ per year & 0.48 \\
\hline Spacer injection & & 0.23 \\
\hline Non-spacer & Reference & \\
\hline Spacer & $0.245(-0.161-0.652)$ & \\
\hline Rectum volume (continuous) & $0.002(-0.008-0.013)$ per cc & 0.67 \\
\hline Monitoring time (continuous) & $0.002(-0.001-0.006)$ per second & 0.22 \\
\hline \multicolumn{3}{|l|}{ Anterior MID } \\
\hline Age (continuous) & $0.008(-0.020-0.036)$ per year & 0.57 \\
\hline Spacer injection & & $0.0074^{\dagger}$ \\
\hline Non-spacer & Reference & \\
\hline Spacer & $0.692(0.199-1.185)$ & \\
\hline Rectum volume (continuous) & $0.001(-0.012-0.014)$ per $c c$ & 0.84 \\
\hline Monitoring time (continuous) & $0.002(-0.003-0.006)$ per second & 0.50 \\
\hline \multicolumn{3}{|l|}{ Posterior MID } \\
\hline Age (continuous) & $0.004(-0.042-0.049)$ per year & 0.87 \\
\hline Spacer injection & & 0.35 \\
\hline Non-spacer & Reference & \\
\hline Spacer & $-0.375(-1.174-0.424)$ & \\
\hline Rectum volume (continuous) & $-0.012(-0.033-0.009)$ per cc & 0.24 \\
\hline Monitoring time (continuous) & $0.002(-0.006-0.009)$ per second & 0.65 \\
\hline \multicolumn{3}{|c|}{ Maximum intrafractional vector length } \\
\hline Age (continuous) & $0.023(-0.040-0.085)$ per year & 0.46 \\
\hline Spacer injection & & 0.42 \\
\hline Non-spacer & Reference & \\
\hline Spacer & $0.441(-0.664-1.547)$ & \\
\hline Rectum volume (continuous) & $-0.010(-0.039-0.019)$ per cc & 0.48 \\
\hline Monitoring time (continuous) & $0.002(-0.008-0.012)$ per second & 0.69 \\
\hline
\end{tabular}


Table 3 (continued)

Abbreviations: MID maximum intrafracitonal displacement, $\mathrm{Cl}$ confidence interval

${ }^{\text {a }}$ By multiple regression analysis

† Statistically significant

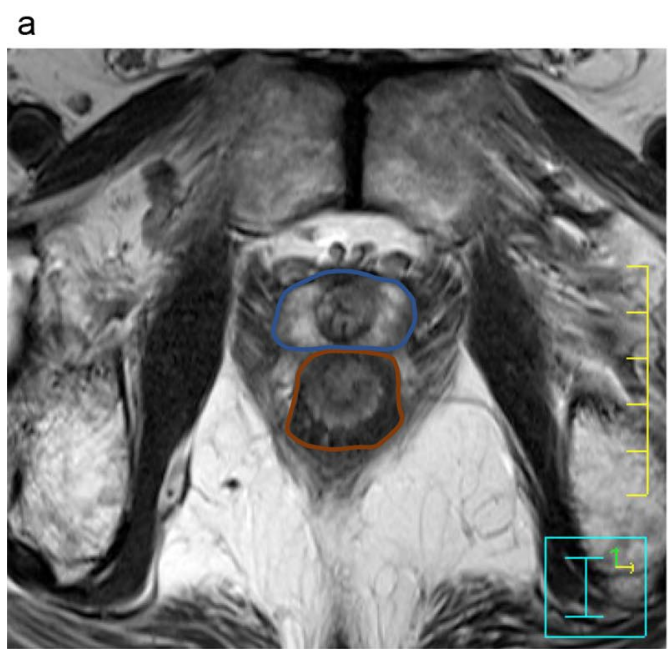

\section{b}

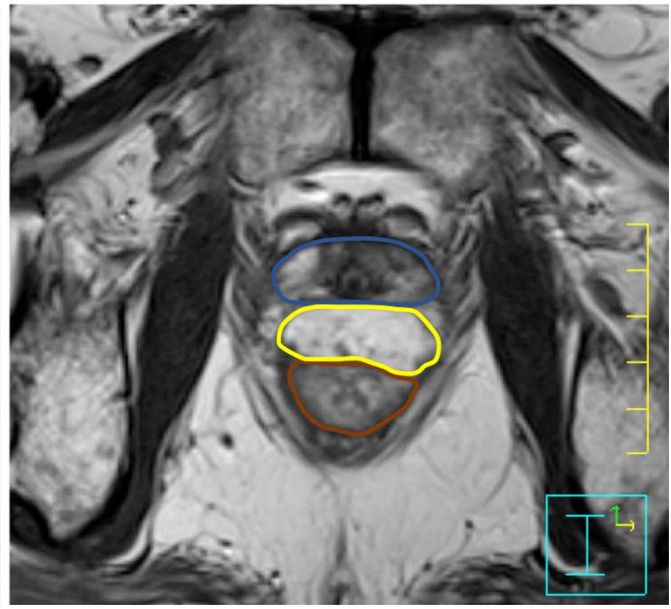

Fig. $2 \mathrm{MRl}$ images of the same patient. a The image before spacer injection. b The image after spacer injection. Prostate (blue), rectum (brown), and spacer (yellow) are shown

treated with the MR-linac based on the 3D cine-MRI and the treatment $\log$ files. They reported that the average drop from the planned dose in D99\% coverage for the CTV was $2.1 \% \pm 2.9 \%$. In our study, the hydrogel spacer increased the superior and anterior MID of the prostate, which may have increased the dose delivered to the area inferior and posterior to the prostate. Because the difference of the MID between the two groups was 0.5$0.7 \mathrm{~mm}$, the dose to the anterior wall of the rectum in the spacer group seems not to have increased due to the recto-prostatic space spread by the spacer. Considering the dosimetric and clinical merit of the hydrogel spacer [24-27], our results do not support routine avoidance of the hydrogel spacer use.

Another limitation of our study was the fact that the quality of our results depends on the accuracy of the Clarity system. The Clarity system has the advantage of not requiring fiducial markers implantation or additional hardware installation and no radiation exposure [38]. The disadvantage of the Clarity system is operator dependence [15]. In our study, every operator had received the training of this system in advance. Zhou et al. [39] investigated the discrepancy between the Clarity system and $\mathrm{CBCT}$ as the positioning device. The average $( \pm \mathrm{SD})$ discrepancies were $-0.03 \pm 5.22 \mathrm{~mm}, 0.18 \pm 2.87 \mathrm{~mm}$, and $0.31 \pm 4.37 \mathrm{~mm}$ in the SI, LR, and AP directions, respectively when the Clarity was transperineally used. Grimwood et al. [38] reported that the median difference between Clarity-defined intrafractional marker locations and portal-imaged marker locations was $0.6 \mathrm{~mm}$. Biston et al. [40] also reported that the mean differences between intrafractional displacements observed on patients with the Clarity system and the intraprostatic electromagnetic transmitters were $\leq 0.55 \mathrm{~mm}$ in all directions except for one patient.

The other limitation was small sample size, in particular the spacer group. Most characteristics were similar between the two groups, but the rectum volume was smaller in the spacer group, which may be due to accidental bias. However, rectum volume was not the independent risk factor of the MIDs according to the multivariate analysis.

\section{Conclusions}

Our findings suggest that maximum intrafractional prostate motion during VMAT-SBRT was larger in patients with hydrogel spacer injection in the superior and anterior directions. Since this difference seemed not to disturb the dosimetric advantage of the hydrogel spacer, we do not recommend routine avoidance of the hydrogel spacer use. Further studies are expected in order to clarify the cause that prostate in patients with hydrogel spacer tends to move during RT, and to find other factors related to intrafractional prostate motion. 


\section{Abbreviations}

ADT: Androgen deprivation therapy; AP: Anterior-posterior; BMI: Body mass index; CBCT: Cone beam computed tomography; CT: Computed tomography; CTV: Clinical target volume; EBRT: External beam radiation therapy; FFF: Flattening filter free; IGRT: Image-guided radiation therapy; IMRT: Intensity modulated radiation therapy; LR: Left-right; mID: Mean intrafractional displacement; MID: Maximum intrafractional displacement; MRD: Maximum rectal diameter; MRI: Magnetic resonance imaging; NCCN: National Comprehensive Cancer Network; PTV: Planning target volume; RT: Radiotherapy; SBRT: Stereotactic body radiation therapy; SD: Standard deviation; SE: Standard error; SI: Superiorinferior; US: Ultrasound; VL: Vector length; VMAT: Volumetric modulated arc therapy; 95th-MID: 95Th percentile maximum intrafractional displacement.

\section{Acknowledgements}

We would like to thank Alisha Huang for careful English proofreading.

\section{Authors' contributions}

SS collected and assembled the data, drafted the manuscript and critically revised the article for important intellectual content. HY supervised all of the above work. MO, RT, YN, YW, and TI helped to interpret and analyze the collected data. OA helped to draft the manuscript. All authors read and approved the final manuscript.

\section{Funding}

Not applicable.

\section{Availability of data and materials}

The datasets used and/or analyzed during the current study are available from the corresponding author on reasonable request.

\section{Declarations}

\section{Ethics approval and consent to participate}

This study was approved by the research ethics committee, University of Tokyo Hospital. Examination number was 3372.

\section{Consent for publication}

Patients gave written consent for data collection and analysis.

\section{Competing interests}

The authors declare that they have no competing interests in association with this study.

Received: 31 March 2021 Accepted: 13 February 2022

Published online: 23 February 2022

\section{References}

1. Sanda MG, Cadeddu JA, Kirkby E, Chen RC, Crispino T, Fontanarosa J, Freedland SJ, Greene K, Klotz LH, Makarov DV, Nelson JB, Rodrigues G, Sandler HM, Taplin ME, Treadwell JR. Clinically localized prostate cancer: AUA/ASTRO/SUO guideline. Part I: risk stratification, shared decision making, and care options. J Urol. 2018;199(3):683-90. https://doi.org/10. 1016/j.juro.2017.11.095.

2. Mottet N, van den Bergh RCN, Briers E, Van den Broeck T, Cumberbatch MG, De Santis M, Fanti S, Fossati N, Gandaglia G, Gillessen S, Grivas N, Grummet J, Henry AM, van der Kwast TH, Lam TB, Lardas M, Liew M, Mason MD, Moris L, et al. EAU-EANM-ESTRO-ESUR-SIOG guidelines on prostate cancer-2020 update. Part 1: screening, diagnosis, and local treatment with curative intent. Eur Urol. 2020. https://doi.org/10.1016/j. eururo.2020.09.042

3. Brenner DJ, Hall EJ. Fractionation and protraction for radiotherapy of prostate carcinoma. Int J Radiat Oncol Biol Phys. 1999;43(5):1095-101. https://doi.org/10.1016/S0360-3016(98)00438-6.

4. Brenner DJ, Martinez AA, Edmundson GK, Mitchell C, Thames HD, Armour EP. Direct evidence that prostate tumors show high sensitivity to fractionation (low alpha/beta ratio), similar to late-responding normal tissue. Int J Radiat Oncol Biol Phys. 2002;52(1):6-13.
5. Arabpour A, Shahbazi-Gahrouei D. Effect of hypofractionation on prostate cancer radiotherapy. Int J Cancer Manag. 2017. https://doi.org/10. 5812/ijcm.12204.

6. Dasu A, Toma-Dasu I. Prostate alpha/beta revisited an analysis of clinical results from 14168 patients. Acta Oncol (Madr). 2012;51(8):963-74. https://doi.org/10.3109/0284186X.2012.719635.

7. Greco C, Pares O, Pimentel N, Louro V, Santiago I, Vieira S, Stroom J, Mateus D, Soares A, Marques J, Freitas E, Coelho G, Seixas M, LopezBeltran A, Fuks Z. Safety and efficacy of virtual prostatectomy with singledose radiotherapy in patients with intermediate-risk prostate cancer results from the PROSINT phase 2 randomized clinical trial. JAMA Oncol. 2021;7(5):700-8. https://doi.org/10.1001/jamaoncol.2021.0039.

8. Mah D, Freedman G, Milestone B, Hanlon A, Palacio E, Richardson T, Movsas B, Mitra R, Horwitz E, Hanks GE. Measurement of intrafractional prostate motion using magnetic resonance imaging. Int J Radiat Oncol Biol Phys. 2002;54(2):568-75. https://doi.org/10.1016/S0360-3016(02) 03008-0.

9. Ghilezan MJ, Jaffray DA, Siewerdsen JH, Van Herk M, Shetty A, Sharpe MB, Jafri SZ, Vicini FA, Matter RC, Brabbins DS, Martinez AA. Prostate gland motion assessed with cine-magnetic resonance imaging (cine-MRI). Int J Radiat Oncol Biol Phys. 2005;62(2):406-17. https://doi.org/10.1016/j. ijrobp.2003.10.017.

10. Boda-Heggemann J, Köhler FM, Wertz H, Ehmann M, Hermann B, Riesenacker N, Küpper B, Lohr F, Wenz F. Intrafraction motion of the prostate during an IMRT session: A fiducial-based 3D measurement with Cone-beam CT. Radiat Oncol. 2008;3(1):1-8. https://doi.org/10.1186/ 1748-717X-3-37.

11. Langen KM, Willoughby TR, Meeks SL, Santhanam A, Cunningham A, Levine L, Kupelian PA. Observations on real-time prostate gland motion using electromagnetic tracking. Int J Radiat Oncol Biol Phys. 2008;71(4):1084-90. https://doi.org/10.1016/j.jirobp.2007.11.054.

12. Willoughby TR, Kupelian PA, Pouliot J, Shinohara K, Aubin M, Roach M, Skrumeda LL, Balter JM, Litzenberg DW, Hadley SW, Wei JT, Sandler HM. Target localization and real-time tracking using the Calypso 4D localization system in patients with localized prostate cancer. Int J Radiat Oncol Biol Phys. 2006;65(2):528-34. https://doi.org/10.1016/j.jirobp.2006.01.050.

13. Kotte ANTJ, Hofman P, Lagendijk JJW, van Vulpen M, van der Heide UA. Intrafraction motion of the prostate during external-beam radiation therapy: analysis of 427 patients with implanted fiducial markers. Int J Radiat Oncol Biol Phys. 2007;69(2):419-25. https://doi.org/10.1016/j. ijrobp.2007.03.029.

14. Pinkawa M, Pursch-Lee M, Asadpour B, Gagel B, Piroth MD, Klotz J, Nussen S, Eble MJ. Image-guided radiotherapy for prostate cancer: Implementation of ultrasound-based prostate localization for the analysis of inter- and intrafraction organ motion. Strahlenther und Onkol. 2008;184(12):679-85. https://doi.org/10.1007/s00066-008-1902-7.

15. Sihono DSK, Ehmann M, Heitmann S, von Swietochowski S, Grimm M, Boda-Heggemann J, Lohr F, Wenz F, Wertz H. Determination of intrafraction prostate motion during external beam radiation therapy with a transperineal 4-dimensional ultrasound real-time tracking system. Int J Radiat Oncol Biol Phys. 2018;101(1):136-43. https://doi.org/10.1016/j. ijrobp.2018.01.040.

16. Richter A, Exner F, Weick S, Lawrenz I, Polat B, Flentje M, Mantel F. Evaluation of intrafraction prostate motion tracking using the Clarity Autoscan system for safety margin validation. Z Med Phys. 2020;30(2):135-41. https://doi.org/10.1016/j.zemedi.2019.12.004.

17. Levin-Epstein R, Qiao-Guan G, Juarez JE, Shen Z, Steinberg ML, Ruan D, Valle L, Nickols NG, Kupelian PA, King CR, Cao M, Kishan AU. Clinical assessment of prostate displacement and planning target volume margins for stereotactic body radiotherapy of prostate cancer. Front Oncol. 2020;10(April):1-9. https://doi.org/10.3389/fonc.2020.00539.

18. Adamson J, Wu Q, Yan D. Dosimetric effect of intrafraction motion and residual setup error for hypofractionated prostate intensity-modulated radiotherapy with online cone beam computed tomography image guidance. Int J Radiat Oncol Biol Phys. 2011;80(2):453-61. https://doi.org/ 10.1016/j.ijrobp.2010.02.033.

19. Wust P, Joswig M, Graf R, Böhmer D, Beck M, Barelkowski T, Budach V, Ghadjar P. Dosimetric implications of inter- and intrafractional prostate positioning errors during tomotherapy. Strahlenther und Onkol. 2017;193(9):700-6. https://doi.org/10.1007/s00066-017-1141-x. 
20. Kontaxis C, de Muinck Keizer DM, Kerkmeijer LGW, Willigenburg T, den Hartogh MD, van der Voort van Zyp JRN, de Groot-van Breugel EN, Hes J, Raaymakers BW, Lagendijk JJW, de Boer HCJ. Delivered dose quantification in prostate radiotherapy using online 3D cine imaging and treatment log files on a combined 1.5T magnetic resonance imaging and linear accelerator system. Phys Imaging Radiat Oncol. 2020;15(May):2329. https://doi.org/10.1016/j.phro.2020.06.005.

21. Wong JR, Gao Z, Uematsu M, Merrick S, Machernis NP, Chen T, Cheng CW. Interfractional prostate shifts: review of 1870 computed tomography (CT) scans obtained during image-guided radiotherapy using CT-onrails for the treatment of prostate cancer. Int J Radiat Oncol Biol Phys. 2008;72(5):1396-401. https://doi.org/10.1016/j.jirobp.2008.03.045.

22. Brown A, Tan A, Cooper S, Fielding A. Obesity does not influence prostate intrafractional motion. J Med Radiat Sci. 2018;65(1):31-8. https://doi.org/ 10.1002/jmrs.255

23. Oates R, Brown A, Tan A, Foroudi F, Lim Joon M, Schneider M, Herschtal A, Kron T. Real-time image-guided adaptive-predictive prostate radiotherapy using rectal diameter as a predictor of motion. Clin Oncol. 2017;29(3):180-7. https://doi.org/10.1016/j.clon.2016.09.019.

24. Babar M, Katz A, Ciatto M. Dosimetric and clinical outcomes of SpaceOAR in men undergoing external beam radiation therapy for localized prostate cancer: a systematic review. J Med Imaging Radiat Oncol. 2021;65:384-97. https://doi.org/10.1111/1754-9485.13179.

25. Armstrong N, Bahl A, Pinkawa M, Ryder S, Ahmadu C, Ross J, Bhattacharyya S, Woodward E, Battaglia S, Binns J, Payne H. SpaceOAR Hydrogel spacer for reducing radiation toxicity during radiotherapy for prostate cancer. A systematic review. Urology. 2021. https://doi.org/10.1016/j.urolo gy.2021.05.013.

26. te Velde BL, Westhuyzen J, Awad N, Wood M, Shakespeare TP. Late toxicities of prostate cancer radiotherapy with and without hydrogel SpaceAOR insertion. J Med Imaging Radiat Oncol. 2019;63(6):836-41. https://doi.org/10.1111/1754-9485.12945.

27. Hall WA, Tree AC, Dearnaley D, Parker CC, Prasad V, Roach M, Lawton CAF. Considering benefit and risk before routinely recommending SpaceOAR. Lancet Oncol. 2021;22(1):11-3. https://doi.org/10.1016/S1470-2045(20) 30639-2.

28. Aminsharifi A, Kotamarti S, Silver D, Schulman A. Major complications and adverse events related to the injection of the spaceOAR hydrogel system before radiotherapy for prostate cancer: review of the manufacturer and user facility device experience database. J Endourol. 2019;33(10):868-71. https://doi.org/10.1089/end.2019.0431.

29. Juneja P, Kneebone A, Booth JT, Thwaites DI, Kaur R, Colvill E, Ng JA, Keall PJ, Eade T. Prostate motion during radiotherapy of prostate cancer patients with and without application of a hydrogel spacer: a comparative study. Radiat Oncol. 2015;10(1):4-9. https://doi.org/10.1186/ s13014-015-0526-1.

30. Picardi C, Rouzaud M, Kountouri M, Lestrade L, Vallée JP, Caparrotti F, Dubouloz A, Miralbell R, Zilli T. Impact of hydrogel spacer injections on interfraction prostate motion during prostate cancer radiotherapy. Acta Oncol (Madr). 2016;55(7):834-8. https://doi.org/10.3109/0284186X.2015 1128118.

31. Cuccia F, Mazzola R, Nicosia L, Figlia V, Giaj-Levra N, Ricchetti F, Rigo M, Vitale C, Mantoan B, De Simone A, Sicignano G, Ruggieri R, Cavalleri S, Alongi F. Impact of hydrogel peri-rectal spacer insertion on prostate gland intra-fraction motion during 1.5 T MR-guided stereotactic body radiotherapy. Radiat Oncol. 2020;15(1):1-9. https://doi.org/10.1186/ s13014-020-01622-3.

32. Suzuki T, Saito M, Onishi H, Mochizuki Z, Mochizuki K, Satani K, Sano N, Aoki S, Marino K, Komiyama T, Takahashi H. Effect of a hydrogel spacer on the intrafractional prostate motion during CyberKnife treatment for prostate cancer. J Appl Clin Med Phys. 2020;21(10):63-8. https://doi.org/ 10.1002/acm2.13005.

33. Hedrick SG, Fagundes M, Robison B, Blakey M, Renegar J, Artz M, Schreuder N. A comparison between hydrogel spacer and endorectal balloon: an analysis of intrafraction prostate motion during proton therapy. J Appl Clin Med Phys. 2017;18(2):106-12. https://doi.org/10. 1002/acm2.12051.

34. Stroom JC, De Boer HCJ, Huizenga H, Visser AG. Inclusion of geometrical uncertainties in radiotherapy treatment planning by means of coverage probability. Int J Radiat Oncol Biol Phys. 1999;43(4):905-19. https://doi. org/10.1016/S0360-3016(98)00468-4.
35. Van Herk M, Remeijer P, Rasch C, Lebesque JV. The probability of correct target dosage: dose-population histograms for deriving treatment margins in radiotherapy. Int J Radiat Oncol Biol Phys. 2000;47(4):1121-35. https://doi.org/10.1016/S0360-3016(00)00518-6.

36. Ballhausen H, Li M, Ganswindt U, Belka C. Shorter treatment times reduce the impact of intra-fractional motion: a real-time 4DUS study comparing VMAT vs. step-and-shoot IMRT for prostate cancer. Strahlenther und Onkol. 2018;194(7):664-74. https://doi.org/10.1007/s00066-018-1286-2.

37. Li H, Zhang X, LiY, Zhu RX. An analytical model for the upper bound estimation of respiratory motion-induced dose uncertainty in spot-scanning proton beam therapy. Med Phys. 2019;46(11):5249-61. https://doi.org/10. 1002/mp.13811.

38. Grimwood A, McNair HA, O'Shea TP, Gilroy S, Thomas K, Bamber JC, Tree AC, Harris EJ. In vivo validation of Elekta's clarity autoscan for ultrasoundbased intrafraction motion estimation of the prostate during radiation therapy. Int J Radiat Oncol Biol Phys. 2018;102(4):912-21. https://doi.org/ 10.1016/j.jijrobp.2018.04.008.

39. Zhou S, Luo L, Li J, Lin M, Chen L, Shao J, Lu S, Ma Y, Zhang Y, Chen W, Liu M, Liu S, He L. Analyses of the factors influencing the accuracy of three-dimensional ultrasound in comparison with cone-beam CT in image-guided radiotherapy for prostate cancer with or without pelvic lymph node irradiation. Radiat Oncol. 2019;14:1-10.

40. Biston MC, Zaragori T, Delcoudert L, Fargier-Voiron M, Munoz A, Gorsse C, Sarrut D, Pommier P. Comparison of electromagnetic transmitter and ultrasound imaging for intrafraction monitoring of prostate radiotherapy. Radiother Oncol. 2019;136:1-8. https://doi.org/10.1016/j.radonc.2019.03. 020.

\section{Publisher's Note}

Springer Nature remains neutral with regard to jurisdictional claims in published maps and institutional affiliations.

Ready to submit your research? Choose BMC and benefit from

- fast, convenient online submission

- thorough peer review by experienced researchers in your field

- rapid publication on acceptance

- support for research data, including large and complex data types

- gold Open Access which fosters wider collaboration and increased citations

- maximum visibility for your research: over $100 \mathrm{M}$ website views per year

At BMC, research is always in progress.

Learn more biomedcentral.com/submissions 